\title{
Novel reactions of aryldiazonium salts. A method for the generation of electrophiles
}

\author{
Andrzej Kostuch, Agnieszka Urban, and Piotr Tomasik \\ Department of Chemistry, University of Agriculture, Mickiewicz Ave., 21, 31120 Cracow, \\ Poland \\ E-mail: rrtomasi@cyf-kr.edu.pl
}

(received 15 Jan 00; accepted 25 Apr 00; published on the web 03 May 00)

\begin{abstract}
Aryldiazonium salts decomposed in alkaline medium in the presence of starch. The hydroxide anions accompanying aryldiazonium cations were complexed by starch. Naked aryldiazonium cations decomposed into molecular nitrogen and arylium cations. The latter reacted into phenols. Since decomposition of aryldiazonium cations was slow, phenols which were formed were coupled by non-decomposed aryldiazonium cations to form arylazophenols.
\end{abstract}

Keywords: Aryldiazonium salts, aryldiazonium cations, phenols

\section{Introduction}

Aryldiazonium salts are known for their instability, particularly under acidic conditions. ${ }^{1-4}$ In aqueous solutions, preferably at elevated temperature, the hydroxyl anion attacks the aryl cation resulting from elimination of molecular nitrogen from the aryldiazonium cation.

$$
[\mathrm{Ar}-\mathrm{N} \equiv \mathrm{N}]^{+} \stackrel{\mathrm{H}^{+}}{\longrightarrow} \mathrm{Ar}^{+}+\mathrm{N}_{2} \uparrow
$$

In alkaline solutions three species (a-c) reside in equilibrium: ${ }^{5-7}$

$$
[\mathrm{Ar}-\mathrm{N} \equiv \mathrm{N}]^{+} \underset{\mathrm{OH}^{-}}{\frac{\mathrm{OH}^{-}}{\rightleftharpoons}} \mathrm{Ar}-\mathrm{N}=\mathrm{N}-\mathrm{OH} \underset{\mathrm{OH}^{-}}{\stackrel{\mathrm{OH}^{-}}{\rightleftharpoons}} \mathrm{Ar}-\mathrm{N}=\mathrm{N}-\mathrm{O}
$$

(a)

(b)

(c)

The position of the equilibrium depends, among other things, on the $\mathrm{pH}$ and the effects of substituents residing on the Ar moiety. ${ }^{5-8}$ 
This paper describes the facile, spontaneous, decomposition of aryldiazonium cations under alkaline conditions in the presence of starch. A slow evolution of nitrogen takes place, and phenols, which are formed as intermediates couple with the non-decomposed diazonium salts to form azodyes.

$$
\begin{aligned}
& {[\mathrm{Ar}-\mathrm{N}=\mathrm{N}]^{+} \mathrm{OH}_{\text {sorbed on starch }}^{-} \longrightarrow \mathrm{Ar}+\mathrm{N}_{2}+\mathrm{OH}^{-} \text {sorbed on starch }} \\
& \mathrm{Ar}^{+}+\mathrm{OH}^{-} \longrightarrow \mathrm{ArOH} \\
& \mathrm{Ar}-\mathrm{OH}+[\mathrm{Ar}-\mathrm{N}=\mathrm{N}]^{+} \longrightarrow \mathrm{Ar}-\mathrm{N}=\mathrm{N}-\mathrm{C}_{6} \mathrm{H}_{4}^{-}-\mathrm{OH} \text { (2- or 4-) } \\
& \sum_{-\mathrm{H}^{+}}[\operatorname{Ar}-\mathrm{N}=\mathrm{N}]^{+} \\
& \mathrm{HO}-\mathrm{C}_{6} \mathrm{H}_{3}(\mathrm{~N}=\mathrm{N}-\mathrm{Ar})_{2}(2,4-)
\end{aligned}
$$

\section{Results and Discussion}

As anticipated, aryldiazonium salts introduced to aqueous alkali did not decompose as deduced from a lack of evolution of nitrogen and unchanged color of the reaction mixture. Also, pouring an aqueous, acidic solution of aryldiazonium salts into an aqueous suspension of starch produced no reaction of the diazonium salt. However, noticeable changes could be observed at $\mathrm{pH}>7$ when an aqueous suspension of starch was maintained on introducing of solution of aryldiazonium salts. Slow evolution of nitrogen begun and the color of the reaction mixture changed from dark yellow or red to brown depending on the decomposing aryldiazonium salt. The decompositions were stopped when the reaction mixtures were acidified. Thus, evidently starch under basic conditions catalyzes the decomposition of aryldiazonium salts.

It is commonly known ${ }^{1-4}$ that aryldiazonium salts are stabilized by resonance and electrical field of the counter anions. Our observation leads to the conclusion that starch forms complexes with hydroxyl anions of aryldiazonium hydroxides formed in alkaline solutions. Destabilized aryldiazonium cations lost molecular nitrogen, generating in this manner arylium cations accepting hydroxyl anions to form phenols. The decomposition of aryldiazonium cations was slow and the phenols formed in this manner coupled with the non-decomposed aryldiazonium cations into arylazophenols. The formation of complexes of $\operatorname{starch}^{9-10}$ and cyclodextrins ${ }^{11}$ preferably with anions rather than cations was already suggested and the behavior of aryldia- 
zonium salts in alkaline solutions of starch can serve as additional prove of this ability of polyand oligosaccharides. In this manner one may assume that starch could be potentially utilized in organic synthesis for generation of electrophiles from ionizing compounds.

In the case of benzenediazonium cation a trace of 2,4-di-(phenylazo)phenol was also formed. With meta-substituted anilines the main products from the coupling of the diazo-component to the para-position (with respect to the hydroxyl group of phenol) were contaminated by minute amounts of products resulting from coupling to the ortho-position as well. Sucsubtle nonselectivity in azocoupling to phenols was already formerly observed. ${ }^{12}$ Another side-reaction was the formation of formazanes, in which the anomeric carbon atoms of the terminal D-glucose units were involved, resembling the behavior of aldehydes in reactions with aryldiazonium salts. ${ }^{13}$ Consequently, the starch left after extraction of the reaction mixture never recovered its colorless appearance. This side reaction as well as the sorption of dyes on $\operatorname{starch}^{14}$ influenced the reaction yields.

\section{Conclusions}

Starch complexes with anions rather than with cations. Therefore, starch could be potentially useful in organic synthesis for generation of electrophiles from ionizing compounds.

\section{Experimental Section}

General Procedures. Either aniline or its derivative (Table) ( 0.05 mole) was placed in solution prepared from conc. hydrochloric acid $(12 \mathrm{~mL})$ diluted with water $(15 \mathrm{~mL})(0.128$ mole of $\mathrm{HCl})$ and cooled to $0-5{ }^{\circ} \mathrm{C}$. An aqueous solution containing 0.05 mole of sodium nitrite was added dropwise with agitation and temperature control until excess of nitric acid was reached as indicated by starch-iodine paper. This solution was then added dropwise with stirring into a suspension of either granular (Niechlów Potato Enterprise, Poland) or potato soluble starch (Sigma, St. Louis, Missouri, U.S.A.) (10-20 g) in water $(150 \mathrm{~mL})$ to which aq. $30 \% \mathrm{NaOH}$ solution was added until $\mathrm{pH} 10$ was reached. $\mathrm{As} \mathrm{NaOH}$ was neutralized by addition of the acidic solution of aryldiazonium salt, a $\mathrm{pH}$ of $8.5-10$ of the reaction mixture was maintained by addition of $30 \%$ aq. $\mathrm{NaOH}$ solution. Nitrogen was liberated as proved by passing its stream through a very diluted aqueous solution of $\mathrm{KMnO}_{4}$ (solution did not decolorize). Simultaneously, a colored solid separated from the suspension (a temperature between 5 and $15{ }^{\circ} \mathrm{C}$ was maintained). When the evolution of nitrogen had ceased, the solid was filtered off, dried in the air and subjected to continuous extraction with diethyl ether, ethanol or acetone. The composition of extracts was controlled with thin-layer chromatographic plates (Merck DC Fertigplatten, Kieselgel $60 \mathrm{~F}_{254}$ ). 
The azodyes prepared in the reaction under study are characterized in the Table.

Table 1. Results of decomposition of aryldiazonium chlorides in alkaline suspension of potato $\operatorname{starch}^{\mathrm{a}}$

\begin{tabular}{ccccccccccc}
\hline $\begin{array}{c}\text { Substituent in } \\
\text { aryl moiety }\end{array}$ & \multicolumn{3}{c}{$\begin{array}{c}\text { Elemental analysis, \% C } \\
\text { N Calcd. Found Calcd. Found Calcd. Found }\end{array}$} & $\begin{array}{c}\text { M.p. } \\
\text { Dtd. Lit. }\end{array}$ & $\begin{array}{c}\text { Yield }^{\mathrm{d}} \\
\%\end{array}$ \\
\hline None & 72.71 & 72.40 & 5.08 & 5.40 & 14.13 & 14.26 & $152^{15}$ & 149 & $<53$ \\
& & & & & & 4.40 & $83^{16}$ & $80^{\mathrm{b}}$ & trace \\
& & & & & 18.5 & 19.4 & $131^{17}$ & $129^{\mathrm{C}}$ & trace \\
4-Me & 74.31 & 74.81 & 6.24 & 6.15 & 12.39 & 12.03 & $112-3^{18}$ & 112 & 37 \\
3-Me & & & & & & 13.06 & $106-7^{19}$ & 104 & n.d. \\
2-Me & & 74.78 & & 5.80 & & 12.60 & $132^{20}$ & 130 & 54 \\
4-NO & 50.01 & 49.60 & 2.80 & 3.10 & 19.45 & 20.16 & $205-7^{21}$ & 201 & 62 \\
2-NO & & 50.35 & & 2.56 & & 19.90 & $186^{22}$ & 184 & n.d. \\
\hline
\end{tabular}

${ }^{a}$ For th e compounds mono-coupling was assumed in the para-position to the hydroxyl group whenever available and in the ortho-position to the hydroxyl group if the para-position was blocked. ${ }^{b}$ The ortho-isomer. ${ }^{c}$ 2,4-Di-(phenylazo)phenol. ${ }^{d}$ For crude products. ${ }^{\mathrm{e}}$ Not determined.

\section{References}

1. Zollinger, H. Azo and diazo chemistry, Interscience Publ.: New York, 1961; Ch. 3, 7, 9, 12.

2. Zollinger, H. Acc. Chem. Res., 1973, 6, 335.

3. Sterba, V. In The chemistry of diazonium and diazo groups, (ed. S. Patai), J. Wiley, Chichester, 1978, Pt. 1, Ch. 2.

4. Engel, A. Houben-Weyl Methoden der organischen Chemie, Georg Thieme Verlag, Stuttgart, 1990, E16a/Teil 2, 1052.

5. Wittwer, C.; Zollinger, H. Helv. Chim. Acta, 1954, 37, 1954.

6. Machackova, O.; Sterba, V.; Valter, K. Coll. Czech. Chem. Commun., 1972, 37, 2197

7. Luchkevich, E.R.; Mileiko, V.E., Bagal, I.L; Eltsov, A.V. Z. Obszch. Khim., 1986, 56, 1574.

8. Lewis, E.S.; Suhr, H. Chem. Ber., 1958, 91, 2350.

9. Tomasik, P.; Schilling, C.H. Adv. Carbohydr. Chem. Biochem., 1998, 53, 263.

10. Lii C.Y.; Tomasik, P.; Hung, W.L.; Lai, V. M.-F. Cereal Chem., submitted.

11. Szejtli, J. Cyclodextrin inclusion complexes, Akademiai Kiado, Budapest, 1984, Ch. 3.

12. Gurczynski, M; Tomasik, P. Acta Chem. Univ. Jagiell., 1991, 35, 19.

13. Kulikov, Y.M.; Yakushina, E.P; Bunt, M.Ya. Zh. Vses. Khim. Obshch., 1978, 24, 205.

14. Tomasik, P.; Schilling, C.H. Adv. Carbohydr. Chem. Biochem., 1998, 53, 345. 
15. Wallach, O.; Kiepenheuer, L. Ber., 1881, 14, 2617.

16. Bamberger, E. Ber., 1900, 33, 3191.

17. Griess, P. Ann., 1866, 137, 87.

18. Noelting, E.; Kohn, O. Ber., 1884, 17, 351.

19. Jacobson, P. Ann., 1896, 287, 187.

20. Noelting, E.; Werner, A. Ber., 1890, 23, 3259.

21. Hodgson, H.H.; Norris, W.H.H. J. Chem. Soc., 1949, 87. 